\title{
The optimal portfolio of start-up firms in venture capital finance
}

\author{
Vesa Kanniainen $^{\mathrm{a}, 1}$, Christian Keuschnigg ${ }^{\mathrm{b}, *, 2}$ \\ ${ }^{a}$ Department of Economics, University of Helsinki, P.O. Box 54, Fin-00014 Helsinki, Finland \\ ${ }^{\mathrm{b}}$ University of St. Gallen (IFF-HSG), Varnbüelstrasse 19, CH-9000 St. Gallen, Switzerland
}

Received 15 September 2001; accepted 1 April 2002

\begin{abstract}
Venture capitalists (VCs) not only finance but also add value to start-up companies. Advising firms is time consuming and creates a trade-off between intensity of advice and portfolio size. We jointly determine the optimal number of portfolio companies and the intensity of managerial advice. Diminishing returns to advice per firm call for a larger portfolio. With progressively increasing managerial effort cost, however, a larger number crowds out advice to each individual firm. As they receive less support, entrepreneurs request a larger profit share, making further portfolio expansion eventually unprofitable. Comparative static analysis shows how optimal portfolio size responds to venture returns and other parameters.
\end{abstract}

(C) 2003 Elsevier Science B.V. All rights reserved.

JEL classification: D82; G24; G32; L19

Keywords: Venture capital finance; Double moral hazard; Company portfolio

\section{Introduction}

It is often claimed that venture capital (VC) makes young firms grow faster, create more value and generate more employment than other start-ups (European Venture Capital Association, 1996). Venture capitalists (VCs) carefully screen firms, structure contracts to strengthen incentives, and monitor firms (Kaplan and Strömberg, 2001). ${ }^{3}$ Empirical

\footnotetext{
${ }^{*}$ Corresponding author. Tel.: +41-71-224-3085/2520; fax: +41-71-224-2670.

E-mail address: christian.keuschnigg@unisg.ch (C. Keuschnigg).

${ }^{1}$ Also affiliated to CESifo.

2 Also affiliated to CEPR and CESifo.

3 Gompers and Lerner $(1999,2001)$ summarize recent research on venture capital.
} 
research in the US has shown indeed that VC backed firms are more innovative and produce more and more valuable patents (Kortum and Lerner, 2000). They are faster in developing their products and introducing them to market. They have a higher rate of executive turnover, reflecting faster managerial professionalization (Hellmann and Puri, $2000,2002)$. This success of the US VC industry is not easily duplicated in other countries, however. A recent empirical study suggests that European VC has grown vigorously in terms of volume invested but apparently had not much influence on growth and employment of their portfolio firms (Bottazzi and Da Rin, 2002). They conclude that the quality of European VC is a more urgent issue than sheer quantity. This raises the question of how incentives in $\mathrm{VC}$ investing are determined. Our paper points to an important trade-off between the number of firms in the company portfolio of a VC and the extent of managerial advice offered to start-up firms.

It is a stylized fact that a typical VC portfolio includes several firms (see Gorman and Sahlman, 1989; Sahlman, 1990; Norton and Tenenbaum, 1993; Reid et al., 1997). How many start-ups should a VC include in her portfolio? We argue that the optimal company portfolio results from a trade-off between the number of firms included and the advisory effort allocated to each one. With diminishing returns to advice per firm, and if firms are identical or not too different, it is better to expand the number of companies rather than concentrating advice on a single project. On the other hand, the VC's effort cost increases progressively as more firms are included. In consequence, advice is easily stretched too thin which reduces the prospects of the portfolio companies and thereby undermines the VC's profits from the portfolio of firms. This "profit destruction effect" eventually stops the desire to expand portfolio size. An optimal trade-off between the number of portfolio companies and the quality of advice offered to each individual firm emerges. This trade-off is particularly important when an increased demand for $\mathrm{VC}$ financing meets a fixed supply of experienced VCs. The skills needed for successful VC investing are difficult and time-consuming to acquire (Gompers and Lerner, 1999, p.4) and are thus likely to be an important constraint in the development of an active VC industry that is able to promote the professionalization of new firms. When more startups with high potential appear and demand for VC support increases, VCs might be tempted to acquire more firms at the cost of quality. This makes them more similar to banks, which do not offer managerial support but tend to finance a much larger number of firms. If this is the case, VC-backed firms will not perform significantly better than other firms as Bottazzi and Da Rin (2002), for example, observed for a sample of European firms.

That portfolio size responds to specific incentives was recently investigated empirically by Cumming (2001) drawing on a sample of Canadian VC firms. He found indeed that portfolio size is significantly affected by a number of proxies for the nonpecuniary benefits and costs of having additional entrepreneurial firms in a $\mathrm{VC}$ portfolio. Results are consistent with the proposition that more intensive monitoring by the $\mathrm{VC}$ gives rise to fewer entrepreneurial firms in the portfolio. The nature of the financing arrangements is also important. The use of equity and convertible instruments, as opposed to debt finance, allows VCs to share in the upside potential of new firms and provides them with powerful incentives to actively support the professionalization and growth of start-up firms. In the US, more than $90 \%$ of the VC backed enterprises are financed with convertible preferred 
stock (Kaplan and Strömberg, 2000). In Germany, which hosts by now the largest VC market in Europe, silent partnerships seem to dominate over the use of convertible, equity like instruments, possibly because of the importance of public-private-partnership agencies $^{4}$ (Bascha and Walz, 2001b). ${ }^{5}$ These observations imply that European VCs might often be endowed with weak incentives for active involvement in their portfolio companies, which might introduce a bias for larger portfolios at the expense of professional support.

The contrasting performance of the VC industry in Europe vs. the US points to the possibility that the industry might very well follow a more intensive or extensive investment approach. An intensive investment strategy would finance only a few portfolio companies but add high value in terms of managerial support. An extensive strategy, in contrast, would go for large portfolios without much involvement in each single company. Our paper investigates this trade-off between portfolio size and extent of VC involvement, which so far has escaped a rigorous analysis in the literature. The empirical findings of Cumming (2001) support the notion that the number of portfolio firms is endogenous. Unfortunately, measures of the quality of VC investments are not available in this study.

The present paper complements this empirical work and explains analytically how a $\mathrm{VC}$ finances and advises an optimal number of portfolio companies. It identifies an important trade-off between portfolio size and quality of $\mathrm{VC}$ finance, as measured by the extent of advice, and explains how this trade-off depends on important structural parameters characterizing the VC industry. Our comparative static analysis reveals how the trade-off between portfolio size and quality of advice changes with shocks to venture returns and other parameters related to the extent of the agency problem. Interestingly enough, the standard argument of diversification in the presence of risk cannot be the only and perhaps even the dominating mechanism in determining the company portfolio of a venture capital firm.

In developing a model of VC activity with double moral hazard, our analysis importantly draws on Repullo and Suarez (1999), Casamatta (1999), Schmidt (1999) and Strobel (2001). These authors assume, like all other contributors in this field, that a VC finances only one entrepreneur. In treating firms as identical, our paper abstracts from issues of screening and selecting start-up firms. An early paper combining adverse selection and moral hazard in VC investing is Amit et al. (1990). These authors, however, do not consider how VCs create value in terms of managerial support. Since only the entrepreneur's effort is variable, moral hazard is one-sided. There is no analysis of portfolio size that might give rise to a trade-off between quantity and quality as in our framework. In Section 2, we now set up the model, characterize the optimal VC portfolio and derive some comparative static results. Section 3 concludes.

\footnotetext{
${ }^{4}$ Labor-sponsored VC funds have the largest portfolios in Canada, pointing to less VC involvement with portfolio firms, see Cumming (2001).

5 These authors point out that the presence of a specialized stock market allowing for a high frequency of IPOs as an exit channel encourages the use of more flexible financial instruments such as convertible securities, see also Bascha and Walz (2001a).
} 


\section{The model}

\subsection{Venture capital activity}

It is assumed that agents are risk-neutral, and that entrepreneurs start one firm each, have no own funds, and are commercially inexperienced. Consequently, they need not only finance, but also managerial advice. A VC finances and advises a portfolio of $i=1, \ldots, n$ start-up companies. For simplicity, we treat all firms as identical. We assume that each one yields a return $R>0$ if successful and zero if it fails. The VC acquires a profit share $1-s_{i}$ and pays a price that covers at least the fixed investment cost $I$. Apart from supplying funds, the $\mathrm{VC}$ is assumed to provide managerial assistance $a_{i}$. The entrepreneur's contribution $e_{i} \in\{0,1\}$ is deemed critical in the sense that her shirking results in business failure with certainty. We thus assume a success probability $P\left(e_{i}, a_{i}\right)=e_{i} p\left(a_{i}\right)$, satisfying $p^{\prime}\left(a_{i}\right)>0>p^{\prime \prime}\left(a_{i}\right)$ and $p\left(a_{i}\right)<1$. Accordingly, active managerial consulting adds value by enhancing the success probability but is subject to decreasing returns to advice within each firm. Such services are costly, however, and the VC's time is scarce. In supporting a portfolio of $n$ companies, the VC's total managerial input amounts to $A=\sum_{i=1}^{n} a_{i}=a n$, where $a_{i}=a$ by symmetry. Effort cost $c(A)$ is assumed increasing and convex in the VC's overall time input. ${ }^{6}$ The entrepreneur's cost is discrete, $l\left(e_{i}\right) \in\{0, \beta\}$. The analysis is simplified with isoelastic specifications,

$$
c(A)=\gamma \frac{A^{1+\varepsilon}}{1+\varepsilon}, \quad p(a)=\frac{a^{1-\theta}}{1-\theta}, \quad \gamma, \varepsilon>0, \quad 0<\theta<1 .
$$

Neither the effort of entrepreneurs nor the extent of VC advice is verifiable and contractible. The informational asymmetry is reflected in the following sequence of events:

\begin{tabular}{c|c|c|c}
$n$ & $s_{i}, b_{i}+I$ & $e_{i}, a_{i}, A$ & $\pi, \pi_{i}^{E}$ \\
\hline$\longrightarrow \square \rightarrow$ & $\rightarrow \square \rightarrow$ & $\rightarrow \square \rightarrow$ & $\rightarrow \square \rightarrow$ \\
\hline portfolio & deal & efforts & results
\end{tabular}

First, the VC chooses a number $n$ of start-up firms and offers to buy a share $1-s_{i}$ for a price $I+b_{i}$ that covers the start-up cost plus some upfront payment $b_{i}$. If the entrepreneur accepts this deal, the company is started. Given $n$ and $s_{i}$, and with investments already

\footnotetext{
${ }^{6}$ The convexity of effort cost is motivated by an increasing opportunity cost or an increasing cost of labor supply of the VC's total time input $A$. It is the key assumption that makes the VC's available time a scarce resource and ultimately limits her desire to expand the portfolio of firms. With linear effort cost, portfolio size would not be determined for the individual VC firm but would be explained only in industry equilibrium as in Keuschnigg (2002).
} 
sunk, efforts $e_{i}$ and $a_{i}$ are chosen, implying a total consulting activity $A$. Finally, risk is resolved and payments distributed. The VC's overall problem is

$$
\begin{aligned}
& \max _{n, s_{i}, b_{i}} \pi=\sum_{i=1}^{n}\left[e_{i} p\left(a_{i}\right)\left(1-s_{i}\right) R-I-b_{i}\right]-c(A) \text { s.t. } \\
& \mathrm{PC}_{i}^{E}: \pi_{i}^{E}=e_{i} p\left(a_{i}\right) s_{i} R-l\left(e_{i}\right)+b_{i}-w \geq 0, \\
& \mathrm{IC}_{i}^{E}: p\left(a_{i}\right) s_{i} R-\beta \geq 0, \\
& \mathrm{IC}^{F}:\left\{a_{i}\right\}=\arg \max \left\{\left[\sum_{i} e_{i} p\left(a_{i}\right)\left(1-s_{i}\right) R\right]-c(A)\right\} .
\end{aligned}
$$

Condition (2.i) is the participation constraint of entrepreneurs. The contract must yield an expected income, less effort cost, at least as high as the forgone wage $w$ that could be earned in industry, giving a nonnegative surplus $\pi_{i}^{E}$. Conditions (2.ii) and (2.iii) reflect the incentive constraints. Given that contracts are already fixed and investments are sunk, agents choose effort to maximize the remaining income that is still at their discretion. Emphasizing the critical nature of the entrepreneurs' effort, their choice is restricted to two alternatives, high effort and shirking. The return on shirking is zero since the firm fails but effort is also saved. The model is solved by backward induction.

\subsection{Advice and profit sharing}

Efforts: Taking the entrepreneur's input as given, the VC advises as in Eq. (2.iii),

$$
\mathrm{IC}^{F}: e_{i} p^{\prime}\left(a_{i}\right)\left(1-s_{i}\right) R=c^{\prime}(A), \quad i=1, \ldots, n .
$$

Efforts are complimentary. By Eq. (2.ii), the entrepreneur's willingness to supply high effort is strengthened if, for any given share $s_{i}$, the VC contributes to a high success probability. The VC, in turn, helps with managerial advice only if the entrepreneur chooses high effort; otherwise, she does not get involved. Should the contract specify a high share $s_{i}$, the entrepreneur's incentives are strengthened while the $\mathrm{VC}$ becomes less keen to expend managerial effort.

Contract: Anticipating how it affects ex post incentives, the contract is arranged one step earlier. The VC obviously wants to acquire a large equity stake at small cost. What is the minimum profit share $s_{i}$ to retain the entrepreneur's incentives, and the smallest price $b_{i}+I$ that makes him accept the deal? The solution is illustrated in Fig 1, which depicts the incentive conditions (Eqs. (2.ii) and (2.iii)) and is formally developed in Appendix A. In varying the equity share, the $\mathrm{VC}$ recognizes that she thereby sets the incentives for her own effort later on, making $a_{i}$ dependent on $s_{i}$ as in Eq. (3). Her problem is, thus, to choose a point on the incentive constraint $\mathrm{IC}^{F}$ in Fig. 1.

Suppose now that both $\mathrm{PC}^{E}$ and $\mathrm{IC}^{E}$ (Eqs. (2.i) and (2.ii)) are slack in the sense that the corresponding conditions do not bind. It is then profitable for the $\mathrm{VC}$ to cut the 


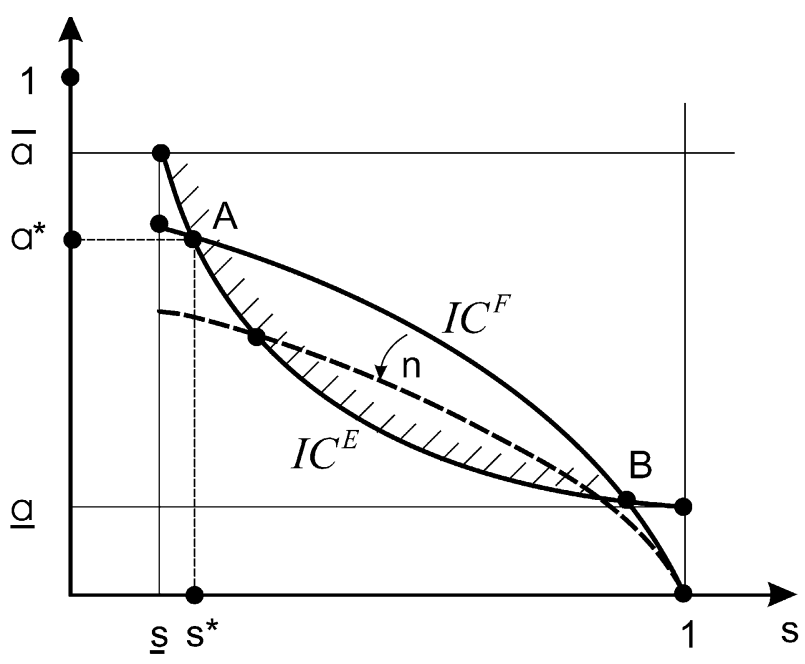

Fig. 1. Optimal advice and profit share.

entrepreneur's share $s_{i}$ and to acquire a larger share for herself which strengthens her ex post incentives to advise more intensively. We have $(\mathrm{d} \pi) /\left(\mathrm{d} s_{i}\right)=-p\left(a_{i}\right) R<0$, since the effect of $s_{i}$ on $a_{i}$ via Eq. (3) leaves profits unchanged at the margin on account of the envelope theorem. Leaving a smaller stake $s_{i}$ to the entrepreneur and moving towards point $A$ thus raises the VC's profits. She will continue to cut $s_{i}$ until $\mathrm{IC}^{E}$ binds. If the entrepreneur's incentive constraint were violated, she would no longer provide her critical effort, and the VC would earn no revenue. The VC must thus offer a profit share sufficiently high to satisfy Eq. (2.ii) and to elicit high effort $e_{i}{ }^{*}=1$. Consequently, point $A$ is the solution and fixes the equity stake and the level of advice. ${ }^{7}$ In designing the contract, the $\mathrm{VC}$ also wants to cut the price $b_{i}+w$ to be paid for this share $1-s_{i}$. With Eq. (2.ii) now binding, the entrepreneur's participation constraint (Eq. (2.i)) emerges as $b_{i} \geq w$. The VC contract is, thus, given by the intersection of the two incentive constraints at point $A$ in Fig. 1 and a price including an upfront payment $b_{i}=w$ that just makes the entrepreneur accept the deal.

The intersection at point $A$ fixes optimal profit sharing and managerial advice. The solution depends on the number of firms that the VC finances and advises as Fig. 1 indicates. Determining optimal portfolio size requires knowing how the contract and subsequent effort levels are adjusted if the $\mathrm{VC}$ acquires more start-ups. For any given profit share $s_{i}$, the VC will obviously expend less advice on each individual firm if she has to tend a larger portfolio $n$ and, therefore, faces higher marginal cost of advice, $c^{\prime}(A)=c^{\prime}(n a)$, see Eq. (3). For this reason, a higher $n$ shifts down the $\mathrm{IC}^{F}$-curve in Fig. 1. A larger portfolio of firms thus induces the $\mathrm{VC}$ to cut back on advice per firm $a$, which requires her to offer a higher profit share $s$ to retain the entrepreneur's critical effort.

\footnotetext{
7 Technically, $B$ also satisfies both constraints. By the previous arguments, however, the VC's profit increases with smaller $s_{i}$, making point $A$ the solution.
} 
When the VC chooses the number of portfolio firms, she must anticipate how a variation in $n$ affects her profits not only directly but also via the effects of $n$ on advice and profit sharing in subsequent stages of the VC cycle. Given the nonlinear nature of the constraints, the solution of Eqs. (2.ii) and (3) as illustrated in Fig. 1 is only implicitly determined. We must thus linearize the model to formally uncover the dependence of advice and profit sharing on portfolio size. The comparative static analysis makes use of the hat notation to indicate percentage changes. For example, $\hat{a} \equiv \mathrm{d} \ln (a)=\mathrm{d} a / a$ is the percentage change of advice relative to an initial equilibrium value of $a$ prior to the change in $n$. Then the success probability $p(a)$ given in Eq. (1) changes according to $\mathrm{d} p=[(1-\theta)$ $p / a] \mathrm{d} a$, or $\hat{p}=(1-\theta) \hat{a}$ in percentage changes. Taking logarithmic differentials of Eqs. (2.ii) and (3) at the symmetric equilibrium solution, i.e. $a_{i}=a, s_{i}=s$, and using Eq. (1), we obtain $^{8}$

$$
\mathrm{IC}^{E}: \hat{s}=\hat{\beta}-\hat{R}-(1-\theta) \hat{a}, \quad \mathrm{IC}^{F}:(\theta+\varepsilon) \hat{a}=\hat{R}-\frac{s}{1-s} \hat{s}-\varepsilon \hat{n} .
$$

A higher return $R$ and a larger profit share $1-s$ for the $\mathrm{VC}$ boost the marginal benefits of advice while a larger portfolio raises the marginal cost of advice. The entrepreneur's profit share may be reduced if her incentives are strengthened by a higher project value or a higher success probability $\hat{p}=(1-\theta) \hat{a}$, but it must be increased if the entrepreneur's effort becomes more costly. Using $\mathrm{IC}^{E}$ to replace $\hat{s}$ in Eq. (4) gives

$$
\hat{a}=\frac{1}{\Psi}\left[\frac{1}{1-s} \hat{R}-\frac{s}{1-s} \hat{\beta}-\varepsilon \hat{n}\right], \quad \Psi \equiv \theta+\varepsilon \frac{s(1-\theta)}{1-s}>0 .
$$

When the VC increases advice because of a higher project value $R$, she boosts the firm's survival chance. A smaller profit share then suffices to retain the entrepreneur's incentive. With her own profit share larger, the VC advises even more intensively. This mutually reinforcing cycle eventually converges to a total effect on advice, provided that $\Psi>0$. As Appendix A shows more precisely, this condition also follows from $\mathrm{IC}^{E}$ being steeper than $\mathrm{IC}^{F}$ in Fig. 1 at point $A$.

Substituting Eq. (5) back into $\mathrm{IC}^{E}$ in Eq. (4) gives

$$
\hat{s}=\frac{1}{\Psi}[(1-\theta) \varepsilon \hat{n}-(1+\varepsilon) \hat{R}+(\theta+\varepsilon) \hat{\beta}] \text {. }
$$

When more firms call for support, the VC advises each one less. As the success rate falls, $\hat{p}=(1-\theta) \hat{a}<0$ by Eq. (5), she must offer higher shares to her entrepreneurial partners to enlist their effort.

The efforts of the VC and the entrepreneurs jointly determine the prospects of start-up firms. Since efforts are intangible and noncontractible, the agreed profit shares must provide incentives for both partners. The entrepreneur must receive a minimum profit share to ensure her discrete effort, which is assumed critical for the firm's prospects. At the

\footnotetext{
${ }^{8}$ Taking the differential of Eq. (2.ii), for example, yields $p^{\prime}(a) s R \mathrm{~d} a+p(a) R \mathrm{~d} s+p(a) s \mathrm{~d} R=\mathrm{d} \beta$. Dividing by $p(a) s R=\beta$ gives $\left[a p^{\prime}(a) / p\right] \mathrm{d} a / a+\mathrm{d} s / s+\mathrm{d} R / R=\mathrm{d} \beta / \beta$. Noting $a p^{\prime}(a)=(1-\theta) p$ by Eq. (1) and using hats gives the version in Eq. (4). By Eq. (1), we have $\hat{p}=(1-\theta) \hat{a}, \hat{p}^{\prime}=-\theta \hat{a}, \hat{c}=(1+\varepsilon) \hat{A}$, and $\hat{c}^{\prime}=\varepsilon \hat{A}$.
} 
same time, the need to share revenues weakens the VC's incentives for managerial advice. The key finding in this section is that the double moral hazard makes incentives for effort inherently interrelated. For example, if the VC starts with a larger number of firms, she faces higher marginal cost of advice and, thus, supports each firm less intensively. The entrepreneur is not directly affected. ${ }^{9}$ However, since a lack of managerial support erodes the firm's success probability, the entrepreneur's expected bonus income declines. To retain incentives for her critical effort, the entrepreneur must receive a larger profit share as is indicated in Fig. 1 by the move from point $A$ to the new equilibrium. As another example, an increase in the entrepreneur's effort cost is not directly relevant for the VC's incentives. However, since the entrepreneur requires a higher share to compensate for increased effort cost, the VC is left with a smaller share that weakens her interest in advising the firm. ${ }^{10}$ A last comparative static result stated in Eqs. (5) and (6) holds that increased rents (say $R$ ) lead to more VC support combined with a smaller incentive compatible profit share of the entrepreneur.

\subsection{Optimal company portfolio}

VCs strive to expand the number of portfolio firms until the contribution of the marginal start-up to profits is zero. Differentiating Eq. (2) and imposing symmetry yields

$$
\pi_{n} \equiv \frac{\mathrm{d} \pi}{\mathrm{d} n}=[p(1-s) R-I-w]-a c^{\prime}-n p R \frac{\partial s}{\partial n} .
$$

Although a larger portfolio dilutes advice in Eq. (5), the marginal effect on profits is zero by the envelope theorem applied to Eq. (2.iii). The square bracket indicates the marginal contribution of an extra firm to VC profits. The second term reflects the additional effort cost from extending managerial support to the marginal firm. The last term captures a profit destruction effect. Having more firms leads the VC to advise each one less, which erodes survival chances. To preserve incentives in face of higher risk, as indicated by a smaller success probability, the VC must cede a higher profit share to entrepreneurs. For more specific results, replace $c^{\prime}$ by Eq. (3), use $a p^{\prime}=(1-\theta) p$ from Eq. (1) and finally insert Eq. (2.ii) to rewrite the first two terms in Eq. (7). Writing the last term as $s p R \hat{s} / \hat{n}$ and using Eq. (6) together with Eq. (2.ii) gives

$$
\pi_{n}=\left[\theta \beta \frac{1-s}{s}-I-w\right]-\beta \frac{(1-\theta) \varepsilon}{\Psi(s)}=0, \quad \pi_{n n}=\frac{\partial \pi_{n}}{\partial s} \frac{\partial s}{\partial n}<0 .
$$

Note that $\Psi^{\prime}(s)=-\frac{1-\theta}{(1-s)^{2}}<0$. All terms in $\pi_{n}$ decline with $n$, via its effect on $s$ on account of Eq. (6), thereby fulfilling the sufficient condition for optimality. The square bracket in Eq. (8) is a profit creation effect, net of effort cost, while the last term is the profit des-

\footnotetext{
${ }^{9}$ Unlike $\mathrm{IC}^{F}$, the $\mathrm{IC}^{E}$-curve is not displaced by a higher $n$ in Fig. 1 . Formally, $\hat{n}$ does not enter $\mathrm{IC}^{E}$ in its differential form in Eq. (4).

${ }^{10}$ Formally, higher effort cost $\beta$ does not enter $\mathrm{IC}^{F}$ in Eq. (4) and, thus, holds no direct effect on the VC's incentive to advise. In terms of Fig. 1 , the $\mathrm{IC}^{F}$-curve remains in place while $\mathrm{IC}^{E}$ shifts up (not drawn). In the new intersection, $s$ is larger and $a$ smaller as is reflected in the formal solution in Eqs. (5) and (6).
} 


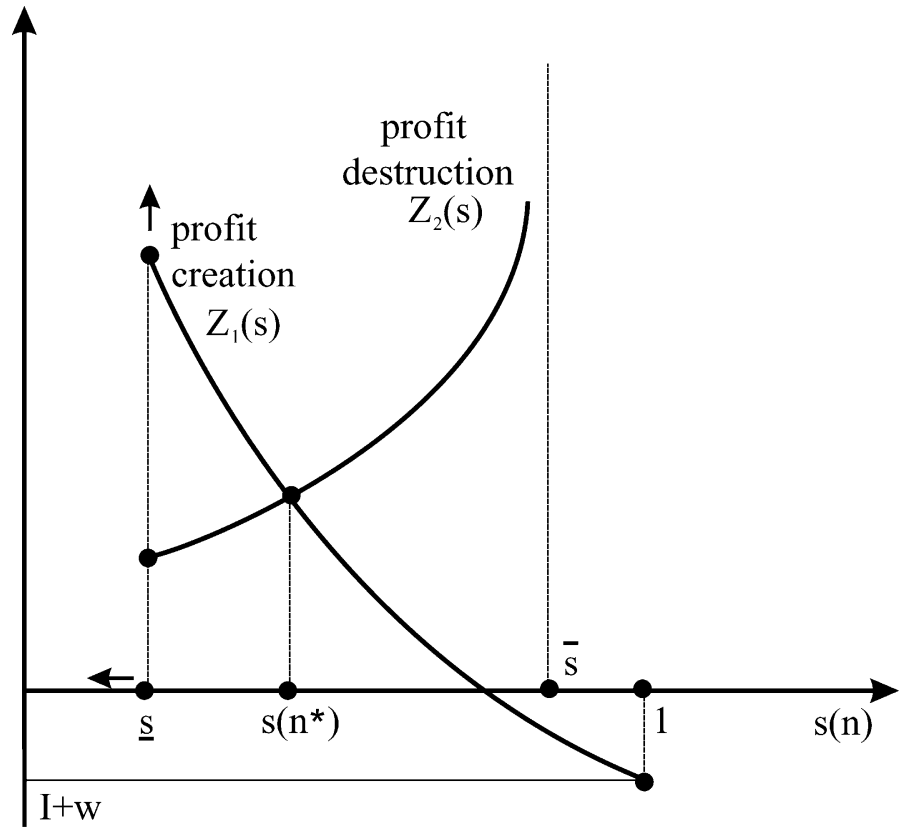

Fig. 2. Optimal number of firms.

truction effect of expanding the number of firms. With few firms in her portfolio, the VC advises rather intensively and can appropriate a large profit share $1-s$ without losing the entrepreneur's effort. The profit creation effect of expanding the company portfolio is then relatively high while the profit destruction effect is small since the erosion of the VC's profit share applies only to a few firms. As more firms are financed and call for support, managerial advice per firm gets diluted on account of Eq. (5), even though the VC expands her overall consulting activity $A{ }^{11}$ With less advice, portfolio companies become riskier. The VC must cede higher profit shares to secure the critical effort of the entrepreneurs. The $\mathrm{VC}$ is thus able to acquire only a smaller stake in each firm for the same price $w+I$, which inflates the profit destruction effect on the entire portfolio of firms. The marginal firm contributes a smaller profit as well, making the profit creation effect smaller. Fig. 2 illustrates how the optimal portfolio balances the profit creation and profit destruction effects, $z_{1}(s)$ and $z_{2}(s)$, as they are defined in condition (8), $\pi_{n}=z_{1}(s)-z_{2}(s)=0$.

Proposition 1. A unique optimal number of portfolio companies exists, $0<n^{*}<\infty$.

Proof. Write Eq. (8) as $\pi_{n}=z_{1}(s)-z_{2}(s)$ where $n$ enters only via its effect on $s(n)$ on account of Eq. (6). At the lowest admissible share $s$ given in Eq. (A.1), we have $z_{1}(\underline{s})=\theta(R-\beta)-I-w$ and $z_{2}(\underline{s})=(1-\theta) \varepsilon \beta / \Psi(\underline{s})$. Since $\Psi^{\prime}<0, \Psi$ gets larger for low values of $s$, making $z_{2}(\underline{s})$ comparatively small. In raising $R$ relative to $\beta$ (see also the discussion of Eq. (A.6)), we make $z_{1}(\underline{s})$ arbitrarily large, and reduce $\underline{s}$. The effect on $\underline{s}$ also

\footnotetext{
${ }^{11}$ Using Eq. (5), we compute $\hat{A}=\hat{a}+\hat{n}=\frac{\Psi_{-\varepsilon}}{\Psi} \hat{n}=\frac{\theta-s}{(1-s) \Psi} \hat{n}>0$. An optimal portfolio satisfying Eq. (8) implies $\theta(1-s) \Psi-s(1-\theta) \varepsilon=(I+w) s \Psi / \beta$. Using $\Psi$, this is $(\theta-s)(\theta+\varepsilon)=(I+w) s \Psi / \beta$ whence $\theta>s$.
} 
squeezes $z_{2}(\underline{s})$ at the lower boundary of $s$. With $R$ appropriately set, we have $z_{1}(\underline{s})>z_{2}(\underline{s})>0$ in Fig. 2. Raising $n$ raises $s$ on account of the "dilution of advice" effect in Eq. (6). Since $z_{1}^{\prime}(s)<0<z_{2}^{\prime}(s)$, the profit creation effect falls while the profit destruction effect becomes ever larger. Since $\Psi(\bar{s})=0$ for $\bar{s}=(\theta+\varepsilon) /(1+\varepsilon)<1, z_{2}(s) \rightarrow \infty$ for $s \rightarrow \bar{s}$. As both schedules are monotonic, a unique solution $n^{*}$ exists in the interval $[\underline{n}, \bar{n}]$ which corresponds to the interval $[\underline{s}, \bar{s}]$.

If effort cost were linear $(\varepsilon=0)$, advice and profit share in Eqs. (5) and (6) would be determined separately for each firm and would be independent of $n$. For this reason, the profit destruction effect would disappear, while the profit creation effect would remain a constant $\pi_{n}=\theta \beta(1-s) / s-I-w \gtrless 0$, leaving the individual portfolio problem indeterminate. If markets rewarded new ventures with sufficiently large returns $R$, the entrepreneur's share could be kept small, making it profitable to acquire more firms. With linear effort cost, the overall consulting activity $A$ per VC could be expanded indefinitely without any increase in marginal cost. The incentives to expand the portfolio could be stopped only if venture returns $R$ fall in industry equilibrium. The convexity of effort cost is thus essential to yield a well-determined number of firms in a VC's portfolio. We now investigate how portfolio size depends on certain parameters.

Proposition 2. The number of portfolio companies $n$ increases with venture returns $R$, but declines with the acquisition price $I+w$ and the entrepreneur's effort cost $\beta$.

Proof. Take the differential of Eq. (8), $-\pi_{n n} \mathrm{~d} n=\pi_{n R} \mathrm{~d} R+\pi_{n Q} \mathrm{~d} Q+\pi_{n \beta} \mathrm{d} \beta$, where $Q=w+I$ stands for the acquisition price. Since $\pi_{n n}<0$ by Eq. (8), the sign of the comparative static effects are equal to the signs of the right hand side coefficients. We have $\pi_{n R}=\pi_{n s} \mathrm{~d} s / \mathrm{d} R>0$ since $\pi_{n s}<0$ by the Proof of Proposition 1 and $\mathrm{d} s / \mathrm{d} R<0$ by Eq. (6). Since price $Q$ does not affect the profit share, Eq. (8) yields $\pi_{n Q}=-1$. Finally, $\beta$ not only appears directly in Eq. (8) but also affects $s$. Rewriting the direct effect $\theta \frac{1-s}{s}-\frac{\varepsilon(1-\theta)}{\psi}$, we have $\pi_{n \beta}=\frac{(\theta-s)(\theta+\varepsilon)}{s \psi}$ $+\pi_{n s} \mathrm{~d} s / \mathrm{d} \beta$ where $\theta>s$ by the previous footnote. Computing $\pi_{n s}$ and substituting from Eq. (6), $\pi_{n s} \mathrm{~d} s / \mathrm{d} \beta=-\left(\frac{\beta \theta}{s^{2}}+\frac{\beta \varepsilon(1-\theta)^{2}}{(1-s)^{2} \psi^{2}}\right) \frac{s}{\beta} \frac{\theta+\varepsilon}{\psi}$. Some further manipulations thus yield $\pi_{n \beta}=-$ $\left(1+s \varepsilon \frac{(1-\theta)^{2}}{(1-s)^{2} \psi^{2}}\right) \frac{\theta+\varepsilon}{\psi}<0$.

When venture returns $R$ increase, VCs raise the level of advice $\left(\alpha_{R}>0\right.$ by Eq. (5)), and are able to acquire for the same price a larger share $1-s$ in the firm $\left(s_{R}<0\right.$ by Eq. (6)). Venture returns thus affect the profit creation effect as noted in Eq. (7) by $(1-s) p-p R s_{R}-a n c^{\prime \prime} a_{R}$ where the last term uses Eq. (3). A larger return directly raises the VC's revenue but also enables her to acquire for the same price a higher stake in the firm. The first two terms thus magnify the profit creation effect. However, advising the portfolio of firms more intensively adds to the effort cost of supporting the marginal firm by anc $^{\prime \prime} a_{R}$ and thereby subtracts from the profit creation effect. ${ }^{12}$ Inspecting Eq. (8) shows that the overall effect is positive. Her willingness to expand the portfolio is further strengthened on account of a smaller profit destruction effect. When projects become more valuable, the VC starts to advise more intensively and cuts the entrepreneurs' profit share

\footnotetext{
${ }^{12}$ The $n$th or marginal firm is the last one added to the company portfolio, or the first one rejected if the VC opts for a smaller portfolio.
} 
on account of lower risk. In obtaining a larger share for herself, the $\mathrm{VC}$ is able to alleviate the profit destruction effect (with $\psi^{\prime}(s)<0, \psi$ rises in Eq. (8) when $s$ falls) which boosts the incentive to expand portfolio size.

Since the acquisition cost is already sunk when the profit share and the level of advice are chosen, it cannot influence them. If the VC must pay a larger price $Q=w+I$ to acquire a given stake in the firm, this directly reduces the profit creation effect and thereby induces the VC to consolidate her portfolio. Finally, if the entrepreneur's effort cost $\beta$ increases the $\mathrm{VC}$ must cede a higher profit share to the entrepreneur to preserve her incentives, $s_{\beta}>0$, which, in turn, destroys her own incentives to provide managerial advice, $a_{\beta}<0$. From Eq. (7), the profit creation effect changes according to $-a n c^{\prime \prime} a_{\beta}-p R s_{\beta}$. Although the savings in managerial effort cost tend to offset the dilution of the VC's profit share, the latter dominates to diminish the profit creation effect. ${ }^{13}$ Since the profit destruction effect is also magnified when a larger share of expected revenue $s p R=\beta$ must be ceded to the entrepreneur, the $\mathrm{VC}$ clearly strives to consolidate her company portfolio.

We finally emphasize that the portfolio decision has important consequences for the structure of VC investing. For example, if start-up investment is more capital intensive, the $\mathrm{VC}$ must pay a larger price to obtain a share in the firm. Although the acquisition cost $Q=w+I$ does not directly affect incentive compatible profit sharing and advice, it makes the $\mathrm{VC}$ to consolidate her portfolio. In financing and advising fewer firms, she is able to advise each one more intensively, which also allows her to squeeze the entrepreneur's profit share. The "dilution of advice" effect is present also in the other experiments of Proposition 2. If ventures are more profitable, the $\mathrm{VC}$ will advise more which also allows her to acquire for the same price a higher share in the firm. When she expands her company portfolio, however, managerial support gets diluted over a larger number of firms and thereby tends to offset the initial increase in advice.

\subsection{Final remarks}

In real life, a venture capitalist finances a small number of start-up enterprises, typically between 5 and 30 (Cumming, 2001). We rationalize this fact based on a model of venture capital finance with double moral hazard. The double moral hazard analysis emphasizes the importance of incentives not only for entrepreneurial effort but also for the venture capitalist's active involvement in their portfolio companies. Our results imply that the optimal number of start-up firms in a venture capital portfolio hinges on parameters relating to the severity of the agency problem. Diminishing returns of managerial advice to the portfolio firm and convexity of managerial effort cost on the part of the venture capitalist are particularly important in shaping the trade-off between portfolio size and extent of managerial advice. A companion paper (Kanniainen and Keuschnigg, 2001) intends to explore how this trade-off might affect the structure of venture capital investing in market equilibrium and thereby shape the evolution of the venture capital industry.

\footnotetext{
${ }^{13}$ Using Eqs. (1), (3), (5) and (6), one may verify $-a n c^{\prime \prime} a_{\beta}-p R s_{\beta}=-\theta(1+\varepsilon) / \Psi<0$.
} 


\section{Acknowledgements}

We appreciate the stimulating comments by seminar participants at the German Economic Association Meeting 2001 and at Universities of St. Gallen and Saarland, Saarbrücken. We are particularly grateful to an anonymous referee for very constructive comments.

\section{Appendix A}

The solution for $a$ and $s$ follows from Eqs. (2.ii) and (3). Since we must impose $p \leq 1$, the form of $p(a)$ in Eq. (1) implies an upper limit for advice of $\bar{a}$. By the same argument, Eq. (2.ii) implies a minimum profit share $\underline{S}$,

$$
\bar{a} \equiv(1-\theta)^{1 /(1-\theta)}, \quad \underline{s}=\beta / R .
$$

Fig. 1 now plots the $\mathrm{IC}^{E}$ curve given in Eq. (2.ii) in $s, a$-space:

$$
\mathrm{IC}^{E}: a=E(s)=\bar{a}(\underline{s} / s)^{1 /(1-\theta)} .
$$

This curve hits the upper limit at $\underline{s}$, i.e. $\bar{a}=E(\underline{s})$. Since the profit share cannot exceed one, it is bounded below by $\underline{a}=E(1)=\bar{a} \underline{s}^{1(1-\theta)}$. It is falling and convex, $E^{\prime}<0<E^{\prime \prime}$. The financier's incentive constraint (Eq. (3)) is

$$
\mathrm{IC}^{F}: a=F(s)=\left[\frac{R}{\gamma n^{\varepsilon}}(1-s)\right]^{1 /(\theta+\varepsilon)} .
$$

This curve is negatively sloped, $F^{\prime}(s)<0$. Since $F^{\prime \prime}(s)=\frac{F^{\prime}(s)(1-\theta-\varepsilon)}{(\theta+\varepsilon)(1-s)} \gtrless 0$, it is concave for $1-\theta<\varepsilon$ and convex otherwise. It satisfies $F(1)=0$. To have an interior solution with $\mathrm{IC}^{E}$ binding as in Fig. 1, we must impose

$$
F(\underline{s}) \leq \bar{a} \Leftrightarrow(1-\theta)^{\theta+\varepsilon}\left(\gamma n^{\varepsilon}\right)^{1-\theta} \geq(R-\beta)^{1-\theta} .
$$

For a solution to exist, the incentive constraints in Fig. 1 must intersect. By equating $F(s)=E(s)$, we get $H(s) \equiv(1-s)^{1-\theta^{\theta+\varepsilon}} s^{\theta+}=[(1-\theta) \beta]^{\theta+\varepsilon}\left(\gamma n^{\varepsilon}\right)^{1-\theta} / R^{1+\varepsilon} \equiv X$. The $H$ schedule satisfies $H(s)>0$ and $H(0)=H(1)=0$. It attains a maximum at $\bar{s}=(\theta+\varepsilon) /$ $(1+\varepsilon)<1$ which follows from $H^{\prime}(s)=\frac{H(s)[\theta+\varepsilon-(1-\varepsilon) s]}{(1-s) s}=0$. Evaluating $H(s)$ at its maximum gives the condition $H(\bar{s})>X$ for the existence of a solution,

$$
H(\bar{s})=\frac{(1-\theta)^{1-\theta}(\theta+\varepsilon)^{\theta+\varepsilon}}{(1+\varepsilon)^{1+\varepsilon}}>\frac{[(1-\theta) \beta]^{\theta+\varepsilon}\left(\gamma n^{\varepsilon}\right)^{1-\theta}}{R^{1+\varepsilon}} .
$$

Under this condition, $H(s)=X$ has two solutions for $s$, meaning that the incentive constraints in Fig. 1 intersect twice. For the solutions to be in the relevant range, Eqs. 
(A.5) and (A.4) must be satisfied simultaneously. Multiplying Eq. (A.5) by $R^{1+\varepsilon} / \beta^{\theta+\varepsilon}$ and comparing with Eq. (A.4) gives the condition

$$
(1-\theta)^{1-\theta}\left(\frac{\theta+\varepsilon}{\beta}\right)^{\theta+\varepsilon}\left(\frac{R}{1+\varepsilon}\right)^{1+\varepsilon}>(1-\theta)^{\theta+\varepsilon}\left(\gamma n^{\varepsilon}\right)^{1-\theta} \geq(R-\beta)^{1-\theta}
$$

Choosing $R$ large and $\beta$ small opens a wide wedge, allowing placement of the middle term to this interval by choice of appropriate values for $\gamma$ and $n$.

Of the two intersection points in Fig. 1, $A$ is the solution. To see this, note that all combinations to the northeast of the $\mathrm{IC}^{E}$-curve are admissible choices for the VC. For any given $s$, the $\mathrm{IC}^{F}$-curve gives the VC's optimal advice according to Eq. (3). Applying the envelope theorem to Eq. (2), the VC maximizes profit by increasing her own profit share, i.e. by reducing $s$. She moves along the $\mathrm{IC}^{F}$-curve to the northwest until the entrepreneur's incentive constraint binds at $A$. Eq. (4) linearizes the two constraints at solution $A$. The condition $\psi>0$ in Eq. (5) reflects the fact that $\mathrm{IC}^{E}$ is steeper than $\mathrm{IC}^{F}$ at $A .^{14}$

The comparative statics in $n$ is also illustrated in Fig. 1. A larger number of firms $n$ leave the $\mathrm{IC}^{E}$-constraint unaffected but shifts down the $\mathrm{IC}^{F}$-condition, moving solution $A$ to the southeast. Advice per firm is reduced, and the entrepreneur's equity share must be increased on account of higher risk.

\section{References}

Amit, R., Glosten, L., Muller, E., 1990. Entrepreneurial ability, venture investments, and risk sharing. Management Science 36, 1232-1245.

Bascha, A., Walz, U., 2001a. Convertible securities and optimal exit decisions in venture capital finance. Journal of Corporate Finance 7, 285-306.

Bascha, A. Walz, U., 2001b. Financing practices in the German venture capital industry. An Empirical Assessment, University of Tuebingen, mimeo.

Bottazzi, L., Da Rin, M., 2002. Venture capital in Europe and the financing of innovative companies. Economic Policy 34, 231-269.

Casamatta, C., 1999. Financing and advising: optimal financial contracts with venture capitalists. University of Toulouse, mimeo.

Cumming, D.J., 2001. The determinants of venture capital portfolio size: empirical evidence. University of Alberta, mimeo.

European Venture Capital Association, 1996. The economic impact of venture capital in Europe, a study by Coopers and Lybrand for EVCA (http: \www.bvca.org).

Gompers, P.A., Lerner, J., 1999. The Venture Capital Cycle. MIT Press, Cambridge.

Gompers, P.A., Lerner, J., 2001. The venture capital revolution. Journal of Economic Perspectives 15, $145-168$.

Gorman, M., Sahlman, W.A., 1989. What do venture capitalists do? Journal of Business Venturing 4, $231-248$.

Hellmann, T., Puri, M., 2000. The interaction between product market and financing strategy: the role of venture capital. Review of Financial Studies 13, 959-984.

Hellmann, T., Puri, M., 2002. Venture capital and the professionalization of start-ups: empirical evidence. Journal of Finance 57, 169-197.

Kanniainen, V., Keuschnigg, C., 2001. Start-up investment with scarce venture capital support. CESifo DP 439, revised.

${ }^{14}$ Note that $E^{\prime}(s)=(-a) /((1-\theta) s)<0$ and $F^{\prime}(s)=(-a) /((\theta+\varepsilon)(1-s))<0$, whence $E^{\prime}(s)<F^{\prime}(s) \Leftrightarrow \psi(s)>0$. 
Kaplan, S.N., Strömberg, P., 2000. Financial contracting theory meets the real world: an empirical analysis of venture capital contracts, NBER WP 7660.

Kaplan, S.N., Strömberg, P., 2001. Venture capitalists as principals: contracting, screening, and monitoring. American Economic Review (Papers and Proceedings) 91, 426-430.

Keuschnigg, C., 2002. Venture capital backed growth. CESifo DP 664 (5).

Kortum, S., Lerner, J., 2000. Assessing the contribution of venture capital to innovation. Rand Journal of Economics 31, 674-692.

Norton, E., Tenenbaum, B.H., 1993. Specialization versus diversification as a venture capital investment strategy. Journal of Business Venturing 8, 431-442.

Reid, G.C., Terry, N.G., Smith, J.A., 1997. Risk management in venture capital investor-investee relations. European Journal of Finance 3, 27-47.

Repullo, R., Suarez, J., 1999. Venture capital finance: a security design approach. CEPR DP No. 2097.

Sahlman, W.A., 1990. The structure and governance of venture-capital organizations. Journal of Financial Economics 27, 473-521.

Schmidt, K.M., 1999. Convertible securities and venture capital finance. Munich, CESifo WP No. 217.

Strobel, P., 2001. Marktsegmentierung zwischen venture capital und Banken. Saarbrücken: University of Saarland, unpublished $\mathrm{PhD}$ thesis. 